\title{
Relationships Between Milk Culture Results and Composite Milk Somatic Cell Counts in Norwegian Dairy Cattle
}

\author{
O. Reksen, ${ }^{* 1}$ L. Sølverød, $†$ and 0. Østerås* \\ *Norwegian School of Veterinary Science, Department of Production Animal Clinical Sciences, PO Box 8146 Dep., N-0033 Oslo, Norway \\ †Tine BA, PO Box 58, N-1430 As, Norway
}

\begin{abstract}
Associations between test-day composite milk somatic cell counts (CMSCC) and results from quarter milk cultures for various pathogens associated with mastitis, including Staphylococcus aureus, Streptococcus spp., coagulase-negative staphylococci (CNS), were investigated. $S$. aureus was dichotomized according to sparse $(\leq 1,500$ colony forming units $/ \mathrm{mL}$ of milk) or rich ( $>1,500$ colony forming units $/ \mathrm{mL}$ of milk) growth of the bacteria. Quarter milk samples were obtained on between 1 and 4 occasions from 2,714 cows in 354 Norwegian dairy herds, resulting in a total of 3,396 samples. Cows included in the study were randomly selected, without regard to current or previous udder health status. Measures of test-day CMSCC were obtained every second month, and related to 3528 microbiological diagnoses at the cow level. Mixed linear regression models incorporating a compound symmetry covariance structure accounting for repeated test-day CMSCC within cow, and a random effect variable on herd level, was used to quantify the relationship between a positive milk culture and the natural logarithm of test-day CMSCC (LnCMSCC). The material was stratified in time periods before $151 \mathrm{~d}$ in milk (DIM) and after 150 DIM. A positive diagnosis for any category of mastitis pathogen was significantly associated with elevated CMSCC. Pathogen positive cows sampled for microbiological diagnosis during the first 150 DIM had higher levels of CMSCC throughout lactation than cows with a positive diagnosis after 150 DIM. Streptococcus spp.-positive milk cultures were associated with steadily elevated values for CMSCC throughout lactation both when sampled before and after 150 DIM. Cows diagnosed with rich growth of $S$. aureus after 150 DIM experienced a characteristic and sharp increase in CMSCC, but this effect was not observed in cows with a positive diagnosis for rich growth
\end{abstract}

Received January 8, 2008.

Accepted April 7, 2008.

${ }^{1}$ Corresponding author: olav.reksen@veths.no of $S$. aureus during the first 150 DIM. A considerable increase in CMSCC in cows positive for CNS during the first part of the lactation period was also observed. The practicability of using CMSCC in a diagnostic test to identify cows with a positive milk culture for mastitis pathogens was also assessed. The sensitivity, specificity, and positive predictive values of the tests were regarded as low when sampling for milk culture was conducted, irrespective of cow level characteristics.

Key words: subclinical, mastitis, cow, somatic cell count

\section{INTRODUCTION}

Bacterial culture is routinely used to diagnose mastitis, and culture results are often used as the basis for the evaluation of quality and the extent of a problem at herd level. Milk cultures might test positive under microbiological analysis due to clinical or subclinical IMI (Harmon, 1994) or due to colonization of the teat canal and cistern with no major involvement of the mammary parenchyma (Persson et al., 1995). Highproducing cows are highly susceptible to subclinical IMI due to Staphylococcus aureus or Streptococcus spp., and losses in milk yield are related to an increase in composite milk somatic cell counts (CMSCC; Miller et al., 2004; Reksen et al., 2007). A positive milk culture for CNS and other minor pathogens does not necessarily result in a significant decrease in milk yield (Reksen et al., 2007), and a relevant question is whether this is due to low inflammatory responses associated with subclinical IMI.

Staphylococcus aureus is the most frequently isolated mastitis pathogen in Norway (Østerås et al., 2006,2007 ), and the success in detecting infected cows is related to the number of colony forming units found during microbiological analysis (Sears et al., 1990). As isolates with low numbers of cfu of $S$. aureus $/ \mathrm{mL}$ of milk are sometimes not reported (Pitkala et al., 2004), it should be determined whether there are differences in the relationships of CMSCC between isolates of $S$. aureus with rich and sparse growth which justify this practice. In comparing randomly selected cows with 
positive microbiological milk cultures, it was observed that cows with sparse growth of $S$. aureus were more likely to be treated, whereas those with rich growth of the bacteria were strongly associated with being culled (Reksen et al., 2006). Furthermore, the combined outcome of treatment and culling for mastitis was shown to be related to a positive diagnosis of Strepococcus spp., whereas the presence of CNS and other minor pathogens did not seem to be associated with either treatment or culling under Norwegian conditions (Reksen et al., 2006).

The obvious biases associated with treatment and culling practices provided a basis for investigating the relationships between CMSCC and milk culture results separately for cows sampled during the first 150 DIM and for cows sampled after 150 DIM. It seemed reasonable to assume that the latter cows would be less likely to be treated during lactation, than cows which were infected during the first half of lactation. Thus, cows with a positive milk culture after 150 DIM may yield a less biased estimate of the pathogen-specific effect on CMSCC, whereas values of CMSCC obtained from cows infected before 151 DIM may display a combined effect of treatment, culling, and immune response.

Previous studies have concluded that CMSCC would be valuable in screening tests to detect cows with IMI, and threshold values in the magnitude of 100,000 to 200,000 cells $/ \mathrm{mL}$ have been used to discriminate between infected and noninfected cows (Dohoo and Leslie, 1991; Sargeant et al., 2001). Because in the present investigation a significant number of cows would be likely to have positive milk culture results due to colonization of the teat canal and cistern in the absence of a response from the udder parenchyma (Persson et al., 1995), a further relevant question would be whether CMSCC would be useful for detecting culturepositive cows when sampling for bacteriological analyses is conducted, irrespective of cow-level characteristics.

The objectives of the present study were therefore as follows: a) to evaluate pathogen-specific changes in CMSCC; b) to study whether the relationship between CMSCC and positive milk culture results differed between diagnoses obtained during the first 150 DIM and after 150 DIM; and c) to examine whether CMSCC results would be of value in predicting a pathogenspecific milk culture result.

\section{MATERIALS AND METHODS}

A survey of quarter milk cultures obtained in 3,538 samplings at cow-level from 354 Norwegian dairy herds was conducted between January 19, 2000, and
January 23, 2001. The study population, design of the survey, and laboratory procedures have been described in detail previously (Østerås et al., 2006). Among all Norwegian dairy farms, $89.2 \%$ were enrolled in the Norwegian Dairy Herd Recording System (NDHRS) at the beginning of the investigation (Østerås, 2002), and the cows in this study were selected from these herds. Both herds and cows were subject to systematic random selection procedures such that every 50th Norwegian dairy herd was selected from the files of the NDHRS for sampling and culture. Cows were sorted within herd according to their unique identity number, and every fifth cow was selected for microbiological sampling. The random selection of cows was carried out 4 times (quarterly) during the investigation period to ensure a representative collection from all 4 seasons. Each cow had the same chance of being selected each season.

Quarter milk samples were collected aseptically by trained advisors from the dairy industry. The individual milk samples were analyzed for growth of microorganisms in accordance with the official procedure in Norway (Aursjø et al., 1993), based on the procedures of the International Dairy Federation (International Dairy Federation, 1987, 1981), with the exception that isolates of $S$. aureus were categorized according to number of cfu at cow-level. Staphylococcus aureus levels were defined as rich when $>15$ cfu was found in at least one sample of $0.01 \mathrm{~mL}$ of milk $(>1,500 \mathrm{cfu} / \mathrm{mL}$ of milk), and as sparse when $\leq 15$ cfu was found upon microbiological analysis in one or more quarters. The $1,500 \mathrm{cfu} / \mathrm{mL}$ threshold value between rich and sparse growth of $S$. aureus was chosen because of its use in the official Norwegian procedure of the National Veterinary Institute (Aursjø et al., 1993). Mastitis pathogens were regarded as present when the following microorganisms were isolated from the milk samples: S. aureus, Streptococcus dysgalactiae, Streptococcus uberis, other Streptococcus spp., coagulase-negative Staphylococcus spp., coliform bacteria (including Escherichia coli), Enterococcus spp., Arcanobacter pyogenes, and Bacillus spp. Staphylococcus aureus was regarded as present when a coagulase positive and $\beta$ hemolytic Staphylococcus spp. was diagnosed. More than one diagnosis was assigned at cow level when microbiological diagnoses differed between quarters in the same cow.

For herds participating in the NDHRS, records are maintained on calving date, parity, test-day CMSCC recorded every second month, culling, and disease history. Norwegian farmers do not have access to veterinary drugs, so the vast majority of treatments are carried out by veterinarians and recorded in the NDHRS. Veterinary diagnoses of clinical mastitis 
were recorded in this study. Primary and secondary reasons for culling were recorded by the farmer in accordance with definitions supplied by the NDHRS (Reksen et al., 2006). The CMSCC was measured in milk samples collected from 2 successive milkings using Fossomatic 5000 (Foss Electric, Hillerød, Denmark). This information was merged with data on the outcome of the microbiological tests. To avoid interfering with management decisions, diagnoses resulting from the microbiological examinations were not reported to the farmer before the study ended. The median herd size in the study was 15.1 cows (range $=3$ to 99 ). Most (97.7\%) of the cows in the study were pure-bred Norwegian Red Cattle. The NDHRS lacked unique identification on 76 microbiological samples from 68 cows and because of missing information for the covariates, the material included in the statistical analyses was reduced to a total of 13,795 CMSCC observations, which were related to 3,528 microbiological analyses from 3,396 samplings in 2,714 cows. One thousand nine hundred forty-four cows were sampled only once, 614 cows were sampled twice, 68 cows were sampled 3 times, and 5 cows were sampled 4 times.

To investigate the diagnostic properties of a test using CMSCC to separate pathogen-positive and pathogen-negative cows, sensitivity and specificity curves were generated by changing the threshold value of the diagnostic test. Sensitivity curves were constructed for pathogen-positive cows in that microbiological diagnoses were examined in intervals of 10,000 cells between CMSCC from 10,000 to 300,000. Similarly, the specificity curves were generated for pathogen-negative diagnoses (Dohoo et al., 2003). Cows with more than one diagnosis at cow-level (microbiological diagnosis differed between quarters in the same cow) were omitted. Two subsets of data were prepared from the main data set:

1. Assessment of the diagnostic properties of a single cell count obtained between $15 \mathrm{~d}$ before and $15 \mathrm{~d}$ after microbiological milk culture. Test-day CMSCC obtained more than $15 \mathrm{~d}$ before microbiological sampling and test-day CMSCC recorded later than $15 \mathrm{~d}$ after sampling for microbiological milk culture were omitted, such that only one single recording for CMSCC was used. The following numbers of observations were included; pathogennegative samples, $\mathrm{n}=1029$; rich growth of $S$. aureus, $\mathrm{n}=162$; sparse growth of $S$. aureus, $\mathrm{n}=$ 154; Streptococcus spp., $\mathrm{n}=60$; CNS/other pathogens, $\mathrm{n}=135$.

2. Assessment of the diagnostic properties of the geometric mean cell count obtained between $60 \mathrm{~d}$ before and $60 \mathrm{~d}$ after microbiological milk culture.
The geometric mean of CMSCC was calculated from up to 3 separate records of CMSCC, and only cows with more than one CMSCC recording during this period were included in the analyses. Geometric mean of the CMSCC was defined as antilog of the value obtained from averaging the natural logarithms of the individual cell counts (Altman, 1995).

The following numbers of observations were included: pathogen-negative samples, $\mathrm{n}=1,155$; rich growth of $S$. aureus, $\mathrm{n}=183$; sparse growth of $S$. aureus, $\mathrm{n}=158$; Streptococcus spp., $\mathrm{n}=65$; CNS/other pathogens, $\mathrm{n}=149$.

\section{Statistical Analyses}

Relationships Between CMSCC and Microbiological Diagnoses. The material was stratified to be able to discriminate between microbiological diagnoses obtained during the first 150 DIM and those obtained at later lactation stages. Multiple records of CMSCC were used for each individual, and the relationships between the outcome variable, the natural logarithm of CMSCC (InCMSCC), and the explanatory variables were assessed using mixed model linear regression for repeated outcomes in PROC MIXED of SAS (Littell et al., 1996). The CMSCC measurements within the same cow were correlated and accounted for by a compound symmetry correlation structure. Other correlation structures were modeled, but the compound symmetry correlation structure resulted in the best model fit. The model also accounted for associations among pathogens when more than one microbiological diagnosis was assigned at the cow level (e.g., the estimated effect of $S$. aureus was adjusted for any association with other pathogens). Clustering at the herd level was accounted for by including herd as a random effect in the models. Only test-day CMSCC up to 305 DIM was used.

Parity was categorized as first, second, and third parity or older. According to the principle of Wood's lactation curve (Wood, 1967), changes in CMSCC throughout the lactation period were expressed by the inclusion of DIM and the natural logarithm of DIM (InDIM) in the models as described by Whist et al. (2007). To account for seasonal effects on CMSCC, testday was transformed to express the radian of a $1-y r$ cycle $(2 \times \pi \times$ test-day/364), and the corresponding cosine and sine functions were both entered into the models (Schukken et al., 1992; Østerås et al., 2006). Previous mastitis history was tested as a dichotomous variable, reflecting whether a cow had been treated for clinical mastitis before it was sampled for microbio- 
logical analysis during the current or the preceding lactation. Clinical mastitis was tested as a dichotomous variable reflecting whether a cow had been treated for clinical mastitis after it was sampled for microbiological analysis within the current 305-d lactation period.

In both models all 1-way interactions were included before the backward elimination procedure was applied, and the variable with the highest $P$-value was excluded. The model was rerun each time a variable was omitted. Variables with a $P$-value $<0.10$ were included in the final models. Confounding was assessed by comparing crude and adjusted parameter estimates. If the estimates varied $>10 \%$, confounding was regarded as being present (Dohoo et al., 2003). The sine and cosine values (seasonal effects) were incorporated in both models. Overall statistical significance was assessed by type III F-test. In all analyses, statistical significance was considered to occur when $P$-values $<0.05$.

The full model expressing associations between $\operatorname{lnCMSCC}$ and microbiological diagnoses obtained during the first 150 DIM were

$$
\begin{gathered}
\text { LnCMSCC }_{\mathrm{tik}}=\alpha+\beta_{1}(\mathrm{DIM})+\beta_{2}(\operatorname{lnDIM}) \\
+\beta_{3}(\text { rich growth of } S . \text { aureus }) \\
+\beta_{4}(\text { sparse growth of } S . \text { aureus }) \\
+\beta_{5}(\text { Streptococcus } \text { spp. }) \\
+\beta_{6}(\text { CNS/other mastitis pathogens }) \\
+\beta_{7}(\text { previous history of clinical mastitis }) \\
+\beta_{8}(\text { clinical mastitis after sampling })+\beta_{9}(\text { parity }) \\
+\beta_{10} \text { sine }(2 \times \pi \times \text { test-day } / 364) \\
+\beta_{11} \operatorname{cosine}(2 \times \pi \times \text { test-day } / 364)+\beta_{12}(\text { parity } \times \mathrm{DIM}) \\
+\beta_{13}(\text { sparse growth of } S . \text { aureus } \times \mathrm{DIM}) \\
+\beta_{14}(\text { Streptococcus } \text { spp. } \times \mathrm{DIM})+\mathrm{Z} \gamma \mathrm{ik}+\mathrm{Z} \gamma \mathrm{k}+e
\end{gathered}
$$

where $t$ corresponds to observation on test day $t$; $i$ to observation at ith individual; and $\mathrm{k}$ to observation at kth herd; Z $\gamma$ ik represents the repeated variation for ith individual at kth herd; $\mathrm{Z} \gamma \mathrm{k}$ the random variation at kth herd; $\alpha=$ intercept; and $e=$ residual error term. The culture-negative cows were used as the control group.

The main effects from the model above were also used in the model expressing associations between $\operatorname{lnCMSCC}$ and microbiological diagnoses obtained after 150 DIM. Interactions between parity $\times$ DIM, rich growth of $S$. aureus $\times$ DIM, and sparse growth of $S$. aureus $\times$ DIM were included in the latter model.
Diagnostic Tests. Pathogen-specific sensitivity curves were plotted against the specificity curve obtained from pathogen-negative cows to identify the CMSCC threshold values, which optimized the diagnostic tests (Dohoo et al., 2003). Sensitivity, specificity, and predictive values of a diagnostic test with threshold values of $>60,000 \mathrm{CMSCC} / \mathrm{mL}$ of milk, and $>200,000 \mathrm{CMSCC} / \mathrm{mL}$ of milk were calculated as described by Dohoo et al. (2003). Milk cultures positive for other than the current pathogen were removed from the data set when pathogen-specific sensitivity, specificity, and predictive values were calculated.

\section{RESULTS}

\section{Microbiological Diagnoses, Clinical Mastitis, and Culling}

The distribution of 3,528 microbiological diagnoses by parity as obtained from 3,396 milk samples at cowlevel is presented in Table 1. None of the samples was positive for Streptococcus agalactiae. Most diagnoses in the category of CNS/other pathogens were CNS; none of the coliform bacteria were diagnosed within $14 \mathrm{~d}$ postpartum. Microbiological findings, stratified by DIM of sampling for milk culture, are reported in Table 2, together with the number of subsequent treatments for clinical mastitis and culling within 305 DIM. The number of diagnoses with culling or treatment for clinical mastitis as endpoint was considerably higher when microbiological sampling was conducted during the first 150 DIM, as compared with microbiological sampling after 150 DIM. Treatment for clinical mastitis was recorded at the day of sampling or during the next day in 7 of the sampled cases. Culling because of mastitis was not observed around the time of sampling.

\section{Relationships Between CMSCC and Microbiological Diagnoses}

The type III F-test assessing the impact of the covariates is presented in Table 3, together with the corresponding $P$-values and parameter estimates. Confounding between the covariates was not apparent in these analyses. The main effect of a positive diagnosis for any category of mastitis pathogen was significantly related to CMSCC, both when sampling was conducted before and after 150 DIM (Table 3). In cows sampled for microbiological milk culture during the first 150 DIM, the cross product between microbiological diagnoses and DIM showed that initially high values for CMSCC declined with time in cows with a positive diagnosis for Streptococcus spp., and the same trend was observed for sparse growth of S. aureus (Table 3, 
Table 1. Distribution of microbiological diagnoses ${ }^{1}$ (percentages in brackets)

\begin{tabular}{|c|c|c|c|}
\hline Microbiological diagnoses & $\begin{array}{c}\text { First parity, } \\
\mathrm{n}=1,431(100)\end{array}$ & $\begin{array}{l}\text { Second parity, } \\
\mathrm{n}=960(100)\end{array}$ & $\begin{array}{l}\geq \text { Third parity, } \\
\mathrm{n}=1,137(100)\end{array}$ \\
\hline No pathogens & $926(65)$ & $615(64)$ & $674(59)$ \\
\hline$>1,500 \mathrm{cfu} / \mathrm{mL}$ of milk of $S$. aureus $^{2}$ & $157(11)$ & $82(9)$ & $104(9)$ \\
\hline Streptococcus dysgalactiae, Streptococcus uberis, and other Streptococcus spp. & $45(3)$ & $51(5)$ & $79(7)$ \\
\hline Coagulase-negative Staphylococcus spp. & $130(9)$ & $102(11)$ & $122(11)$ \\
\hline Other mastitis pathogens ${ }^{3}$ & $11(1)$ & $9(1)$ & $16(1)$ \\
\hline
\end{tabular}

\footnotetext{
${ }^{1}$ Quarter milk samples were obtained in a total of 3,396 samplings, generating 3,528 microbiological diagnoses at the cow-level.

${ }^{2}$ Coagulase-positive Staphylococcus spp. categorized in rich $(>1,500$ colony forming units $=\mathrm{cfu} / \mathrm{mL}$ of milk) or sparse $(\leq 1,500 \mathrm{cfu} / \mathrm{mL}$ of milk) growth of the bacteria.

${ }^{3}$ Enterococcus spp., Arcanobacter pyogenes, Bacillus spp., and coliform bacteria including Escherichia coli.
}

Figure 1). Estimates of CMSCC did not decline with time in cows with a positive milk culture for rich growth of $S$. aureus or in cows positive for CNS/other pathogens (Table 3, Figure 1). The cross product between rich growth of $S$. aureus and DIM showed increasing values for CMSCC by DIM in cows that were sampled after 150 DIM (Table 3, Figure 2). A positive milk culture for Streptococcus spp. or CNS/other pathogens did not alter CMSCC by DIM in cows sampled during the latter half of the lactation period (Table 3, Figure 2). The cross product between sparse growth of $S$. aureus and DIM was borderline nonsignificant (Table 3).

\section{Relationships Between CMSCC, and Stage of Lactation, Parity, Clinical Mastitis, and Season}

An initial decrease of CMSCC was followed by rising cell counts by increasing DIM. This was adjusted for by the significant terms DIM and InDIM (Table 3, Figure 1, and Figure 2) in both models. The effect of parity, as modeled by the terms parity and the cross product between parity and DIM, was significantly related to CMSCC in both strata (Table 3). History of clinical mastitis before sampling for bacteriological milk culture and clinical mastitis after microbiological diagnosis were both significantly related to CMSCC levels in both models. Seasonal effects on CMSCC were also apparent in both strata (Table 3). The average CMSCC was highest during the summer quarter (161,100 cells $/ \mathrm{mL})$ and lowest during the spring quarter $(145,900$ cells $/ \mathrm{mL})$, whereas intermediate values were recorded for the fall $(151,000$ cells $/ \mathrm{mL})$ and winter $(149,700$ cells $/ \mathrm{mL})$ quarters. The mean and standard error $( \pm \mathrm{SE})$ of the CMSCC was $148.82( \pm 4.65)$ for the first 150 DIM and $154.27( \pm 4.06)$ for the period between 150 and 305 DIM.

\section{Diagnostic Tests}

Both sensitivity and specificity were maximized at a CMSCC of approximately 60,000 . The properties of diagnostic tests aimed at correctly identifying cows with positive milk culture results by threshold values of $>60,000$ and $>200,000 \mathrm{CMSCC} / \mathrm{mL}$ of milk are recorded in Table 4. No major differences were observed between estimates of the specificity based on one single CMSCC and the geometric mean CMSCC. The specificity increased almost $30 \%$ when $>200,000$ $\mathrm{CMSCC} / \mathrm{mL}$ of milk was used as threshold level for the

Table 2. Distribution of microbiological diagnoses stratified by days in milk (DIM) of milk sampling, number of subsequent treatments for clinical mastitis and culling within 305 DIM (number of microbiological diagnoses with culling because of mastitis within 305 DIM as final end point is reported in parentheses)

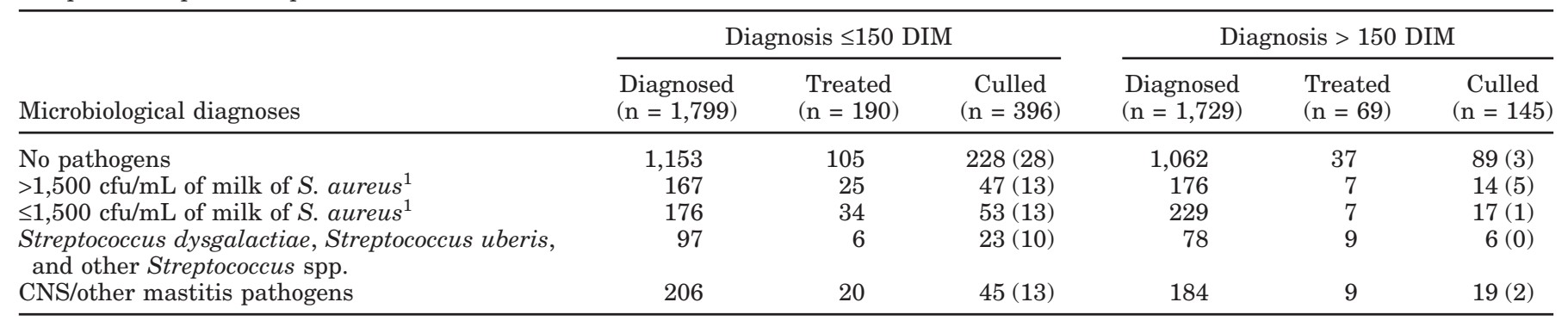

${ }^{1}$ Coagulase-positive Staphylococcus spp. categorized in rich $(>1,500$ colony forming units $=\mathrm{cfu} / \mathrm{mL}$ of milk) or sparse $(\leq 1,500 \mathrm{cfu} / \mathrm{mL}$ of milk) growth of the bacteria. 
Table 3. Estimates $(\beta)$ of the natural logarithm of the composite milk somatic cell count (lnCMSCC) reported for DIM, the natural logarithm of DIM (lnDIM), history of clinical mastitis, clinical mastitis after microbiological diagnosis, diagnosis upon microbiological milk culture, the cross product between microbiological diagnosis and DIM, parity, the cross product between parity and DIM, and seasonal effects on CMSCC as expressed by sine and cosine functions of the radian of a 1 -yr cycle $(2 \times \pi \times \text { test-day/364 })^{1}$

\begin{tabular}{|c|c|c|c|c|c|c|}
\hline \multirow[b]{2}{*}{ Item } & \multicolumn{3}{|c|}{$\mathrm{DIM} \leq 150(\mathrm{n}=6,610)$} & \multicolumn{3}{|c|}{ DIM >150 (n = 7,185) } \\
\hline & $\beta$ & $F$ & $P$ & $\beta$ & $F$ & $P$ \\
\hline Intercept & 5.1494 & - & - & 5.1197 & - & - \\
\hline DIM & 0.0063 & 236.58 & $<0.01$ & 0.0060 & 236.86 & $<0.01$ \\
\hline $\operatorname{lnDIM}$ & -0.3839 & 125.53 & $<0.01$ & -0.3929 & 128.81 & $<0.01$ \\
\hline History of mastitis & 0.0869 & 5.34 & 0.02 & 0.1569 & 23.80 & $<0.01$ \\
\hline Mastitis after milk culture & 0.3832 & 66.02 & $<0.01$ & 0.2803 & 14.84 & $<0.01$ \\
\hline$>1,500$ cfu $S$. aureus $^{2}$ & 0.5415 & 127.94 & $<0.01$ & 0.3216 & 14.37 & $<0.01$ \\
\hline$\leq 1,500$ cfu $S$. aureus ${ }^{2}$ & 0.5042 & 43.22 & $<0.01$ & 0.1987 & 5.53 & 0.02 \\
\hline Streptococcus spp. & 0.8958 & 51.16 & $<0.01$ & 0.5358 & 82.78 & $<0.01$ \\
\hline CNS or other pathogens & 0.5555 & 140.32 & $<0.01$ & 0.2727 & 41.88 & $<0.01$ \\
\hline No pathogens & 0 & - & - & 0 & - & - \\
\hline$>1,500 \mathrm{cfu} S$. aureus $\times$ DIM & $\mathrm{NA}^{3}$ & NA & NA & 0.0020 & 15.76 & $<0.01$ \\
\hline$\leq 1,500$ cfu $S$. aureus $\times$ DIM & -0.0008 & 3.41 & 0.07 & 0.0008 & 2.93 & 0.09 \\
\hline Streptococcus spp. $\times$ DIM & -0.00131 & 5.03 & 0.03 & NA & NA & NA \\
\hline First parity & -0.3713 & 18.55 & $<0.01$ & -0.3252 & 14.70 & $<0.01$ \\
\hline Second parity & -0.2827 & & & -0.1971 & & \\
\hline$\geq$ Third parity & 0 & & & 0 & & \\
\hline First parity *DIM & -0.0014 & 11.49 & $<0.01$ & -0.0014 & 11.94 & $<0.01$ \\
\hline Second parity *DIM & 0.0003 & & & 0.0002 & & \\
\hline$\geq$ Third parity $*$ DIM & 0 & & & 0 & & \\
\hline Sin $2 \times \pi \times($ test-day/364) & 0.0022 & 0.01 & 0.91 & -0.0530 & 9.29 & $<0.01$ \\
\hline $\operatorname{Cos} 2 \times \pi \times($ test-day/364 $)$ & -0.0479 & 5.75 & 0.02 & -0.0344 & 3.59 & 0.06 \\
\hline
\end{tabular}

${ }^{1}$ Overall $F$-values and $P$-levels are reported for the Type III test.

${ }^{2}$ Coagulase-positive Staphylococcus spp. categorized in rich (>1,500 cfu/mL of milk) or sparse $(\leq 1,500 \mathrm{cfu} /$ $\mathrm{mL}$ of milk) growth of the bacteria.

${ }^{3} \mathrm{NA}=$ not analyzed.

determination of pathogen-positive cultures compared with a threshold level of $>60,000 \mathrm{CMSCC} / \mathrm{mL}$ of milk. Corresponding decreases in the sensitivity were observed (Table 4).

Whereas the sensitivity in diagnosing rich growth of $S$. aureus by CMSCC was similar for one single CMSCC and the geometric mean CMSCC, one single CMSCC seemed better for the diagnosis of sparse growth of $S$. aureus. The positive predictive value for any mastitis pathogen was close to $60 \%$ at a threshold value of $>200,000 \mathrm{CMSCC} / \mathrm{mL}$ of milk (Table 4).

\section{DISCUSSION}

\section{Microbiological Diagnoses, Clinical Mastitis, and Culling}

The covariates expressing clinical mastitis before and after sampling for microbiological milk culture were found to be significantly associated with CMSCC in the present investigation. This is in accordance with numerous previous studies (Harmon, 1994; Koivula et al., 2005; Whist et al., 2007). The number of clinical cases of mastitis at the time of sampling for microbiological analysis was negligible in the present study, which would be expected with the random sampling procedures used. Several of the mastitis pathogen isolates would be due to subclinical IMI, defined as an infection with no visible changes in the appearance of the milk or the mammary gland, but milk production decreases, bacteria are present in the secretion, and inflammatory changes in the milk can be detected by special tests, such as cell count (Harmon, 1994; National Mastitis Council, 1996). We would also expect a considerable number of the mastitis pathogens isolates in this investigation to be due to colonization of the teat canal and cistern, along with an absence of, or only limited, inflammatory response (Persson et al., 1995).

The prevalence of positive $S$. aureus milk cultures was higher in this investigation than in a comparable Finnish investigation (Pitkala et al., 2004). The difference in prevalences between the Norwegian and Finnish study may be due to the fact that isolates with sparse growth of $S$. aureus were not reported in the latter study, whereas all isolates of $S$. aureus were included in our material. A more detailed discussion of the microbiological diagnoses and cluster effects in the present study has been published (Østerås et al., 2006). A recent publication has reported a significant association between milk culture results and treat- 


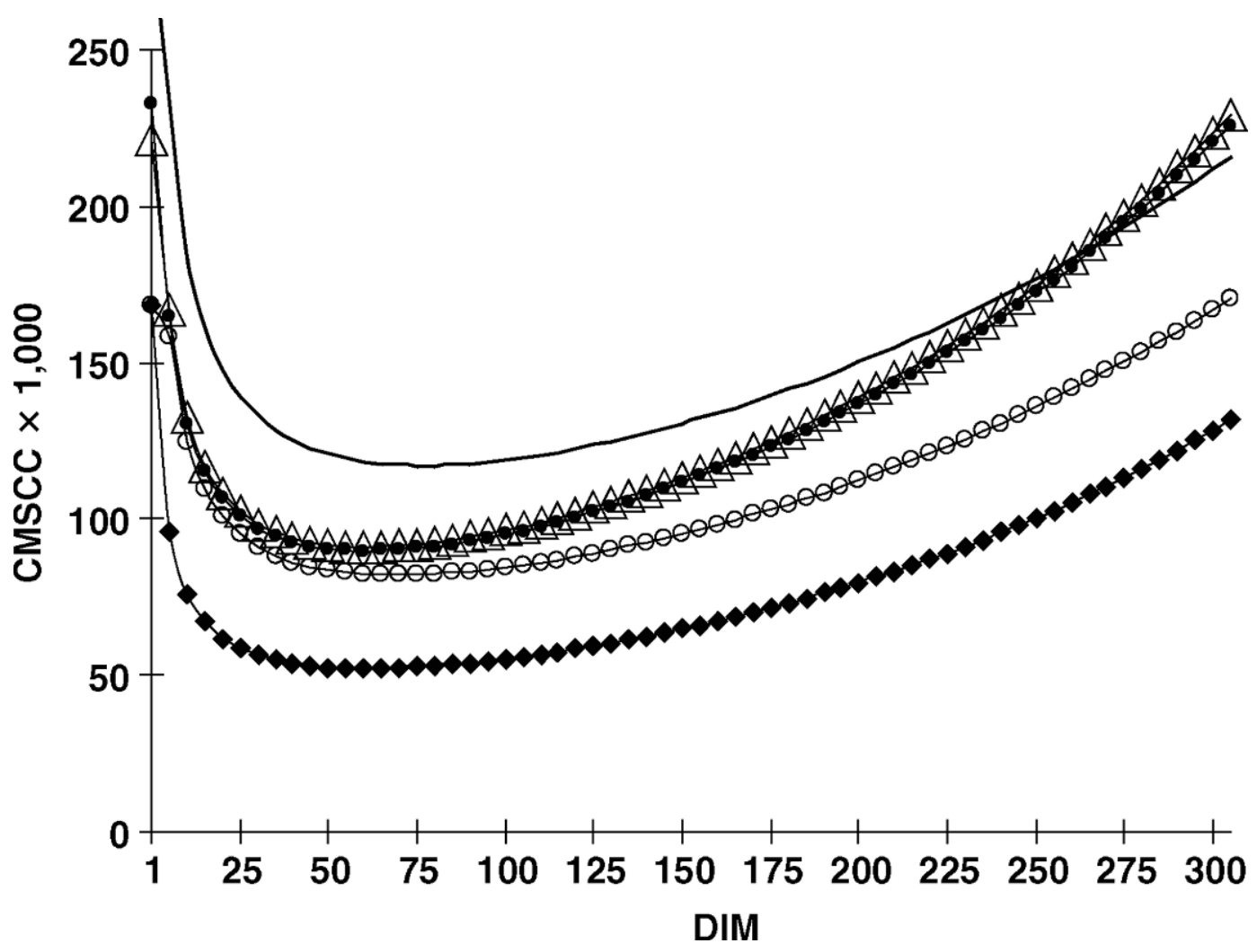

Figure 1. Test-day composite milk somatic cell count (CMSCC) by days in milk (DIM) estimated from Table 3 for third parity or older cows without a recent or previous history of mastitis. Milk cultures were obtained during the first 150 DIM. Milk culture negative cows $(\diamond)$, rich growth of $S$. aureus $(\bullet)$, sparse growth of $S$. aureus $(\bigcirc)$, Streptococcus spp. (-), and CNS, including other mastitis pathogens $(\triangle)$. Coagulase-positive Staphylococcus spp. categorized in rich (>1,500 cfu/mL of milk) or sparse ( $\leq 1,500 \mathrm{cfu} / \mathrm{mL}$ of milk) growth of the bacteria.

ment for clinical IMI and culling in randomly selected cows (Reksen et al., 2006). Similarly, the number of treated or culled cows in the sampled material of the current study, was higher among animals diagnosed with a positive milk culture during the first 150 DIM, than among cows sampled during the later half of the 305-d lactation period. Cases of mastitis during the later stages of lactation are possibly more likely to be treated at drying off than during lactation. The fact that most cows are in calf after 150 DIM probably decreases the culling rate during the later stages of lactation.

\section{Relationships Between CMSCC and Microbiological Diagnoses}

When selecting cows for breeding, Norwegian farmers tend to be considerably influenced by SCC, as milk price premiums are paid at bulk milk tank when SCC $<230,000$ cells $/ \mathrm{mL}$ of milk. Thus, the values for CMSCC in the current investigation are relatively low, although comparable with previous investigations (Laevens et al., 1997; de Haas et al., 2004; Whist et al., 2007). Microbiological analyses were conducted at quarter level; however, because the NDHRS does not record these variables at quarter level, comparisons between microbiological diagnoses and CMSCC were conducted at cow-level. It is important that this limitation is not neglected when interpreting the findings of the study.

As with previous studies on clinical and subclinical IMI, this investigation predicted an increase in CMSCC in pathogen-positive milk cultures in comparison with CMSCC in cows with a negative diagnosis of mastitis pathogens (Laevens et al., 1997; de Haas et al., 2004). A common denominator across categories of microbiological diagnoses were higher estimates for CMSCC throughout the entire lactation period among cows that were sampled for microbiological diagnosis during the first 150 DIM compared with cows sampled after 150 DIM. This is probably a reflection of infection having a greater impact on udder parenchyma when they occur during peak lactation, and persistence of the problem. This observation was most evident among cows with a Streptococcus spp. diagnosis. The fact that CMSCC was also markedly elevated from the 


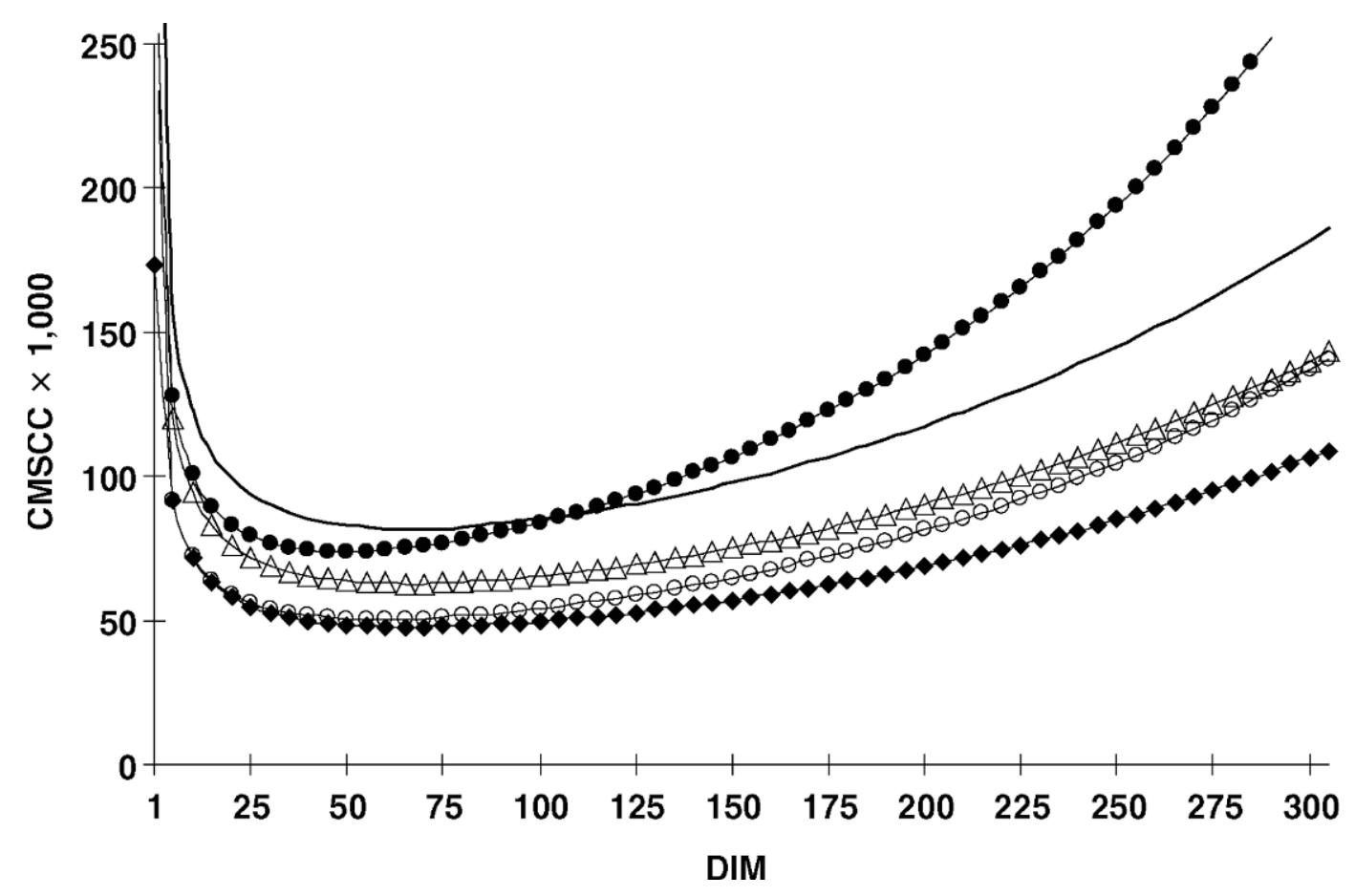

Figure 2. Test-day composite milk somatic cell count (CMSCC) by days in milk (DIM) estimated from Table 3 for third parity or older cows without a recent or previous history of mastitis. Milk cultures were obtained after 150 DIM. Milk culture negative cows ( ), rich growth of $S$. aureus $(\bullet)$, sparse growth of $S$. aureus $(\bigcirc)$, Streptococcus spp. (-), and CNS, including other mastitis pathogens $(\triangle)$. Coagulasepositive Staphylococcus spp. categorized in rich ( $>1,500 \mathrm{cfu} / \mathrm{mL}$ of milk) or sparse $(\leq 1,500 \mathrm{cfu} / \mathrm{mL}$ of milk) growth of the bacteria.

first days of lactation among cows that tested positive for Streptococcus spp. after 150 DIM emphasizes the persistence of these bacteria and their ability to induce elevated cell counts over a prolonged period. Similar findings have been previously reported (Whist et al., 2007).

A positive association between CMSCC and the cross product of DIM and rich growth of $S$. aureus occurred in cows that were found positive for $S$. aureus after 150 DIM. However, a corresponding increase in CMSCC by time was not observed when rich growth of $S$. aureus was diagnosed in cows sampled during the first 150 DIM. Positive milk cultures for $S$. aureus and Streptococcus spp. have been previously noted to be associated with both culling and treatment for clinical mastitis (Reksen et al., 2006, 2007). The difference in the shape of the CMSCC lactation curve derived from cows that were found positive for rich growth of $S$. aureus before $150 \mathrm{DIM}$ and after 150 DIM is probably due to a higher rate of treatment and culling during the first half of the lactation period. Thus, the estimates from the latter half of the lactation period may provide the most accurate impression of the effect of a positive milk culture for rich growth of $S$. aureus on CMSCC in cows that have been sampled irrespective of cow-level characteristics. The same reasoning can be applied to the CMSCC estimates from cows with a positive diagnosis for Streptococcus spp., in that CMSCC decreased by time during the first 150 DIM, and no interaction with time was found for Streptococcus spp.-positive cows after 150 DIM. However, infections during the early versus later lactation stages may also elicit different physiological responses in the udder.

The CMSCC lactation curve derived from cows with diagnoses for CNS/other pathogens is almost identical to the lactation curve derived from cows with rich growth of S. aureus during the first 150 DIM, whereas considerably lower estimates were obtained for CMSCC when CNS/other pathogens were diagnosed after 150 DIM. Previous studies of culling and milk yield in randomly sampled cows did not show any effect of CNS/other pathogens on culling rate or milk yield (Reksen et al., 2006, 2007). Thus, a higher culling and treatment rate among $S$. aureus positive cows is a probable explanation for the similarity in these CMSCC lactation curves. However, the present investigation also demonstrated that CNS/other pathogens have a considerable potential to increase CMSCC in cows that were found to be positive during the first part of the lactation period. Excluding coliform bacteria from the analyses yielded identical estimates, and 
Table 4. Sensitivity (Se), specificity (Sp), positive predictive value (PV+) of diagnostics tests with composite milk somatic cell count (CMSCC) as predictor of infection status when threshold values were set at $>60,000$ cells $/ \mathrm{mL}$ and $>200,000$ cells $/ \mathrm{mL}^{1}$

\begin{tabular}{|c|c|c|c|c|c|c|c|c|}
\hline \multirow[b]{2}{*}{ Microbiological diagnosis } & \multicolumn{4}{|c|}{$>60,000$ cell $/ \mathrm{mL}$} & \multicolumn{4}{|c|}{$>200,000$ cells $/ \mathrm{mL}$} \\
\hline & $\mathrm{Se}(\%)$ & $\mathrm{PV}+(\%)$ & $\mathrm{Se}(\%)$ & $\mathrm{PV}+(\%)$ & $\mathrm{Se}(\%)$ & $\mathrm{PV}+(\%)$ & $\mathrm{Se}(\%)$ & $\mathrm{PV}+(\%$ \\
\hline$>1,500 \mathrm{cfu} / \mathrm{mL}$ of milk of $S$. aureus $^{4}$ & 62.4 & 21.0 & 64.6 & 20.9 & 36.4 & 36.5 & 31.7 & 36.2 \\
\hline CNS/other mastitis pathogens & 65.2 & 18.1 & 61.1 & 21.7 & 25.9 & 23.5 & 14.1 & 17.0 \\
\hline All pathogens & 62.1 & 45.6 & 63.3 & 45.7 & 30.5 & 60.7 & 26.5 & 59.6 \\
\hline
\end{tabular}

the fact that coliform bacteria were not diagnosed within $14 \mathrm{~d}$ postpartum suggests that the primary reason for the observed increase in CMSCC was CNS. This may indicate that recommendations for antimicrobial treatment for IMI caused by CNS could vary according to lactation stage.

de Haas et al. (2004) proposed that pathogen-specific changes in level and duration of SCC might be useful for distinguishing between pathogens in cases of clinical mastitis. In our study, pathogen-specific changes in level, duration, and development of CMSCC might be identified among cows sampled after 150 DIM because CMSCC values obtained from cows sampled during this period seemed to be less biased by culling and treatment decisions. A Streptococcus spp.-positive milk culture after 150 DIM was associated with elevated values for CMSCC throughout the entire lactation period whereas cows diagnosed with rich growth of $S$. aureus after 150 DIM experienced a characteristic and sharp increase in CMCC through a significant interaction with DIM. The CMSCC values for cows diagnosed with sparse growth of $S$. aureus and CNS/ other pathogens after 150 DIM were of the same magnitude throughout the lactation period and consequently discrimination between them from CMSCC results is probably not possible.

Previous reports verify that IMI caused by $S$. aureus involves a prolonged period of elevated SCC, due to chronic and subclinical IMI (Harmon, 1994). Sears et al. (1990) were unable to detect differences in SCC between groups of experimentally infected cows shedding less than 1,000, and more than 2,000, cfu of $S$. aureus $/ \mathrm{mL}$ of milk. This finding has been attributed to cyclic changes of SCC (Sears et al., 1990; Daley et al., 1991). However, a difference in both magnitude and development of CMSCC by time was observed between cows with a positive diagnosis for rich and sparse growth of $S$. aureus in both strata of our study. A more pronounced effect on CMSCC was associated with rich growth of the bacteria after 150 DIM. Taken together, there are indications that discrimination between rich and sparse growth of $S$. aureus can provide useful information in studies of subclinical IMI and inflammatory response.

\section{Relationships Between CMSCC, and Stage of Lactation, Parity, Clinical Mastitis, and Season}

The estimated CMSCC in the current investigation increased by parity, as has been reported previously (de Haas et al., 2004; Whist et al., 2007). Laevens et al. (1997) found higher SCC in primiparous cows than pluriparous cows during the first month in milk (MIM), and hypothesized this to be due to a lower frequency of IMI in pluriparous cows that were routinely treated with intramammary antibiotic treatment at drying off. In our investigation, higher CMSCC were recorded among pluriparous than primiparous cows during the first MIM, which might also be explained by the theory above because intramammary therapy is not applied routinely at drying off in Norway.

As stated in previous studies (Harmon, 1994; Laevens et al., 1997; de Haas et al., 2004), the increase in CMSCC toward the end of the lactation period was lower in primiparous cows than pluriparous cows. In fact, in our study, second parity cows displayed a higher relative increase in CMSCC toward the end of 


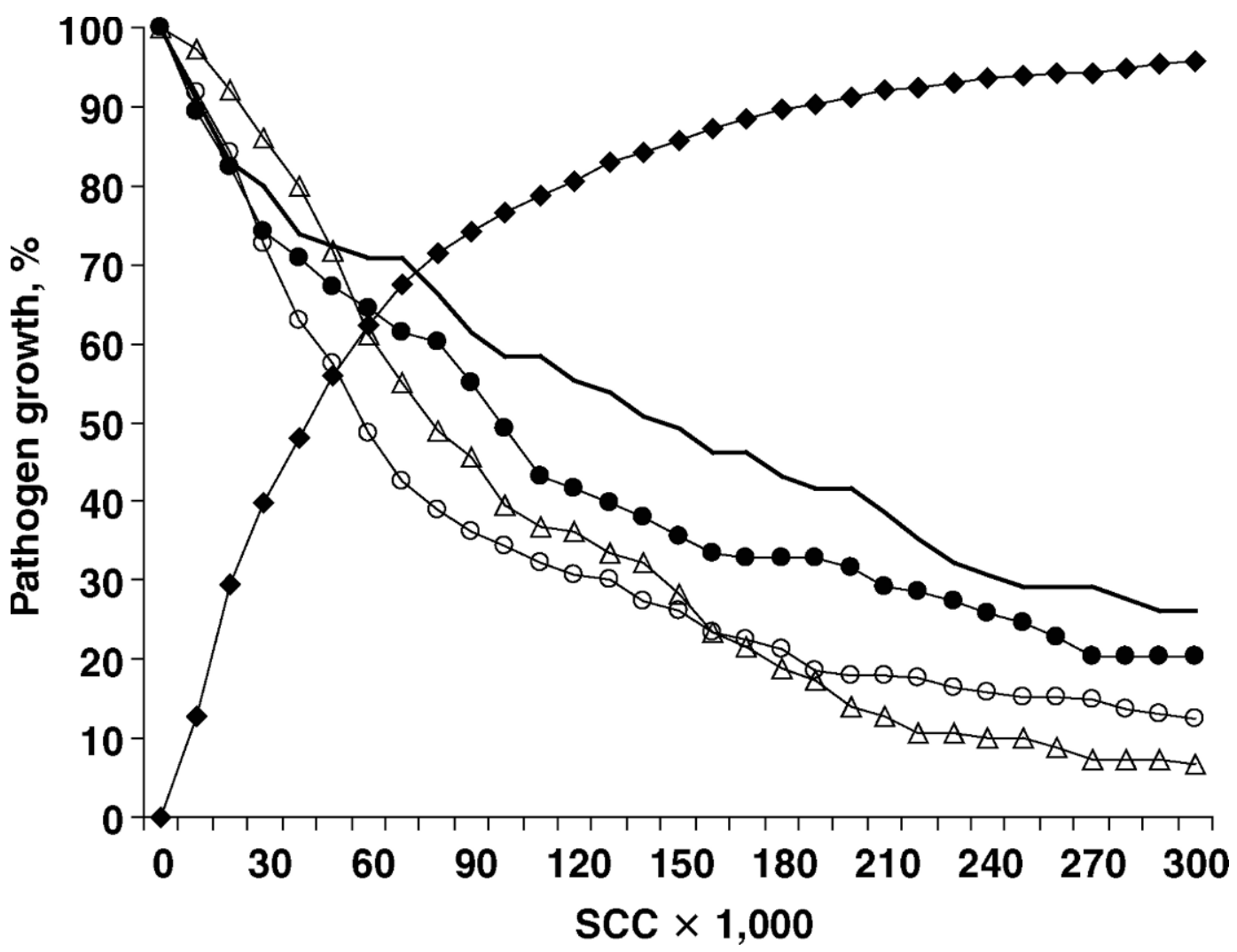

Figure 3. Sensitivity curves for a diagnostic test with the geometric mean composite milk somatic cell count (CMSCC) as determinant of a positive diagnosis for rich growth of $S$. aureus $(\boldsymbol{\bullet}, \mathrm{n}=183)$, sparse growth of $S$. aureus $(\bigcirc, \mathrm{n}=158)$, Streptococcus $\mathrm{spp}$. (一, n = 65), and $\mathrm{CNS} /$ mastitis pathogens $(\triangle, \mathrm{n}=149)$. Coagulase-positive Staphylococcus spp. categorized in rich ( $>1,500 \mathrm{cfu} / \mathrm{mL}$ of milk) or sparse $(\leq 1,500 \mathrm{cfu} / \mathrm{mL}$ of milk) growth of the bacteria. Test-day CMSCC were obtained within the time period from $60 \mathrm{~d}$ before to $60 \mathrm{~d}$ after sampling for microbiological milk culture. The optimum cut-off points for the tests are displayed by the point of intersection with the specificity curve for milk culture negative cows $(\diamond, \mathrm{n}=1,155)$.

the lactation period than was found among third parity or older cows, whereas CMSCC decreased in primiparous cows relative to older cows.

Annual changes in SCC have been described previously (Harmon, 1994). In Norway, the summer seems to be a challenging period because relatively high values for CMSCC were found during this period. Besides the fact that higher temperature and humidity make conditions more amenable for bacterial growth, we also hypothesize that increases in CMSCC may be related to lower dry matter content of the manure during this period of the year.

\section{Diagnostic Tests}

In the current investigation of randomly sampled cows, the optimum sensitivity and specificity was obtained at CMSCC threshold values of around 60,000 cells/mL (Figure 3), which is lower than that previously reported from studies that have used SCC for detecting IMI. Optimum threshold values during early lactation have been reported as being as low as 100,000 cells/mL (Sargeant et al., 2001), whereas corresponding values throughout lactation have been assessed to be around 200,000 cells/mL (Dohoo and Leslie, 1991). The current investigation aims at investigating threshold values general for all lactation stages, as samples are obtained throughout lactation, and the mean CMSCC values do not differ between the periods before and after 150 DIM.

Previous studies have concluded that SCC would be a valuable screening test to detect cows with IMI during the early postpartum period (Sargeant et al., 2001). Although CMSCC was significantly associated with microbiological diagnosis throughout lactation, we found that the gross ability for a single CMSCC to detect mastitis pathogens with sufficient accuracy was limited in our material and was similarly limited when the geometric mean of multiple samples was used. This is probably due to several of the microbiologically positive cows in our investigation having colonization of the teat canal and cistern with limited inflammatory 
response (Persson et al., 1995), rather than IMI, which is more likely to increase CMSCC. It has been shown that local elevations of SCC in teat cisterns infected with a high dose of $S$. aureus diminish after a few days, so that limited differences in overall SCC are to be expected from the local inflammatory response of the teat cistern and teat canal from a high and low infectious dose (Persson et al., 1995). The positive predictive value provides the percentage of samples that are both microbiologically positive and have a CMSCC value above a given cutoff. The predictive value of a positive test increased to approximately $60 \%$ at a CMSCC threshold of 200,000 when the presence of any pathogen was assessed. However, the observed increase from almost $46 \%$ at a threshold value of 60,000 was obtained at the expense of a low sensitivity.

In the current investigation, CMSCC values were obtained before and after sampling for microbiological milk culture. This assumes that microbiologically positive cows would have harbored the infection for some time both before and after sampling. Ideally one should have obtained samples for microbiological milk culture and CMSCC simultaneously, but this was not possible with the available resources. Other approaches, such as using CMSCC values obtained exclusively before, or exclusively after, microbiological diagnosis were also applied and yielded results similar to those currently presented. Interestingly, the properties of a diagnostic test for the diagnosis of sparse growth of $S$. aureus varied between a single CMSCC and the geometric mean of multiple samples, with the latter being considerably less sensitive. This is probably because a low number of colonies of $S$. aureus are more frequently associated with transient colonization/IMI. Also, the limitation of bimonthly instead of monthly assessments of CMSCC should be taken into consideration when the geometric mean cell counts are used for the diagnostic of IMI.

The relationship between predictive values of the test and prevalence of bacteria was verified, in that the less prevalent diagnosis (Streptococcus spp.) also had the lowest predictive values, despite its higher values for sensitivity. Staphylococcus aureus is the most frequently isolated mastitis pathogen under Norwegian conditions (Østerås et al., 2007), and this is also mirrored in the reported predictive values. Predictive values are population specific, and a diagnostic test for Streptococcus spp. in populations with a higher number of IMI caused by this group of pathogens is likely to perform better, despite the present results not being encouraging in terms of detecting positive cows from CMSCC alone.

\section{CONCLUSIONS}

A strong relationship between microbiological diagnosis of mastitis pathogens in milk samples and CMSCC levels was demonstrated in a random sample of the Norwegian cow population, similar to those previously reported from clinical and subclinical IMI. Pathogen-specific changes in level, duration, and development of CMSCC were also identified. A diagnostic test for milk culture results using CMSCC was of relatively low sensitivity and specificity for all microbiological diagnoses, probably due to a high number of cows with transient colonization of the teat canal and cistern with negligible impact on CMSCC. More sophisticated methods should be developed to identify with acceptable accuracy those cows that are asymptomatic, but microbiologically positive.

\section{ACKNOWLEDGMENTS}

This study was supported by a grant from the Research Council of Norway. We thank the advisors at TINE Norwegian Dairies for supplying us with all milk samples. Access to production and health data was provided by the Norwegian Dairy Herd Recording System and the Norwegian Cattle Health Services in Agreement Number 1 in 2002.

\section{REFERENCES}

Altman, D. G. 1995. Practical statistics for medical research. 1st ed. Chapman \& Hall, London, UK.

Aursjø, J., D. Lindheim, O. Reksen, T. Skjervheim, T. Slettbakk, L. Sølverød, and S. Waage. 1993. Laboratorierutiner for mastittdiagnostikk ved Statens veterinære laboratorier. Statens veterinære laboratorier, Oslo, Norway.

Daley, M. J., E. R. Oldham, T. J. Williams, and P. A. Coyle. 1991. Quantitative and qualitative properties of host polymorphonuclear cells during experimentally induced Staphylococcus aureus mastitis in cows. Am. J. Vet. Res. 52:474-479.

de Haas, Y., R. F. Veerkamp, H. W. Barkema, Y. T. Grohn, and Y. H. Schukken. 2004. Associations between pathogen-specific cases of clinical mastitis and somatic cell count patterns. J. Dairy Sci. 87:95-105.

Dohoo, I. R., and K. R. Leslie. 1991. Evaluation of changes in somatic cell counts as indicators of new intramammary infections. Prev. Vet. Med. 10:225-237.

Dohoo, I. R., W. Martin, and H. Stryhn. 2003. Veterinary epidemiologic research. 1st ed. Transcontinental, Charlottetown, Prince Edward Island, Canada.

Harmon, R. J. 1994. Physiology of mastitis and factors affecting somatic cell counts. J. Dairy Sci. 77:2103-2112.

International Dairy Federation. 1981. Laboratory methods for use in mastitis work. Int. Dairy Fed., Brussels, Belgium.

International Dairy Federation. 1987. Bovine Mastitis. Definition and guidelines for diagnosis. Int. Dairy Fed., Brussels, Belgium.

Koivula, M., E. A. Mantysaari, E. Negussie, and T. Serenius. 2005. Genetic and phenotypic relationships among milk yield and somatic cell count before and after clinical mastitis. J. Dairy Sci. 88:827-833.

Laevens, H., H. Deluyker, Y. H. Schukken, L. De Meulemeester, R. Vandermeersch, E. De Muêlenaere, and A. De Kruif. 1997. Influence of parity and stage of lactation on the somatic cell 
count in bacteriologically negative dairy cows. J. Dairy Sci. 80:3219-3226.

Littell, R. C., G. A. Milliken, W. W. Stroup, and R. D. Wolfinger. 1996. SAS system for mixed models. Page 87 in SAS Institute Inc., Cary, NC.

Miller, R. H., H. D. Norman, G. R. Wiggans, and J. R. Wright. 2004. Relationship of test-day somatic cell score with test-day and lactation milk yields. J. Dairy Sci. 87:2299-2306.

National Mastitis Council. 1996. Current concepts of bovine mastitis. National Mastitis Council, Madison, WI.

Østerås, O. 2002. Helsekortordninga 2001. Nor. Vet. Tidsskr. 114:481-492.

Østerås, O., K. P. Forshell, N. E. Svendsby, L. E. Ruud, and A. O. Refsdal. 2007. Norwegian Cattle Health Recording System, Annual Statistics, 2006 (Helsetjenesten for storfe, årsrapport, 2006).

Østerås, O., L. Solverod, and O. Reksen. 2006. Milk culture results in a large Norwegian survey-Effects of season, parity, days in milk, resistance, and clustering. J. Dairy Sci. 89:1010-1023.

Persson, K., B. Amolina, and P. Jonsson. 1995. Inflammation in the bovine teat cistern induced by Staphylococcus aureus. Zentralbl. Veterinarmed. B 42:435-442.

Pitkala, A., M. Haveri, S. Pyorala, V. Myllys, and T. HonkanenBuzalski. 2004. Bovine mastitis in Finland 2001-Prevalence, distribution of bacteria, and antimicrobial resistance. J. Dairy Sci. 87:2433-2441.

Reksen, O., L. Solverod, A. J. Branscum, and O. Osteras. 2006. Relationships between milk culture results and treatment for clinical mastitis or culling in Norwegian dairy cattle. J. Dairy Sci. 89:2928-2937.

Reksen, O., L. Sølverød, and O. Østerås. 2007. Relationships between milk culture results and milk yield in Norwegian dairy cattle. J. Dairy Sci. 90:4670-4678.

Sargeant, J. M., K. E. Leslie, J. E. Shirley, B. J. Pulkrabek, and G. H. Lim. 2001. Sensitivity and specificity of somatic cell count and California Mastitis Test for identifying intramammary infection in early lactation. J. Dairy Sci. 84:2018-2024.

Schukken, Y. H., K. E. Leslie, A. J. Weersink, and S. W. Martin. 1992. Ontario bulk milk somatic cell count reduction program. 1: Impact on somatic cell counts and milk quality. J. Dairy Sci. 75:3352-3358.

Sears, P. M., B. S. Smith, P. B. English, P. S. Herer, and R. N. Gonzalez. 1990. Shedding pattern of Staphylococcus aureus from bovine intramammary infections. J. Dairy Sci. 73:2785-2789.

Whist, A. C., O. Osteras, and L. Solverod. 2007. Streptococcus dysgalactiae isolates at calving and lactation performance within the same lactation. J. Dairy Sci. 90:766-778.

Wood, P. D. P. 1967. Algebraic model of the lactation curve in cattle. Nature 216:164-165. 